\title{
TO STUDY THE IMPACT OF SOCIAL MEDIA ON SOCIETY USING STATISTICAL TECHNIQUES
}

\author{
Prakash S. Chougule \\ Associate Professor \\ Department of Statistics \\ Rajarshi Chhatrapati Shahu College \\ Kolhapur (MS), India
}

\author{
Sarika P. Magdum \\ Research Student \\ Department of Statistics \\ Rajarshi Chhatrapati Shahu College \\ Kolhapur (MS), India \\ Bhakti R. Dhongade \\ Research Student \\ Department of Statistics \\ Rajarshi Chhatrapati Shahu College \\ Kolhapur (MS), India
}

\author{
Tejaswi S. Kurane \\ Assistant Professor \\ Department of Statistics \\ Rajarshi Chhatrapati Shahu College \\ Kolhapur (MS), India
}

\author{
Pruthviraj D. Nikam \\ Research Student \\ Department of Statistics \\ Rajarshi Chhatrapati Shahu College \\ Kolhapur (MS), India
}

\author{
Ajinkya C. More \\ Research Student \\ Department of Statistics \\ Rajarshi Chhatrapati Shahu College \\ Kolhapur (MS), India
}

Article DOI: https://doi.org/10.36713/epra4959

\begin{abstract}
Social media is a platform for people to discuss their issues and opinions. Before knowing the aspects of social media people must have to know what is social media? Social media are computer tools that allow people to share or exchange information's, ideas, images, videos and even more with each other through a particular network. In this paper we cover all aspects of social media with its positive and negative effect. It gives people a way to stay in touch with people who live far away. It lets people share fun, interesting and informative content. It gives businesses a way to engage with customers.
\end{abstract}

KEYWORDS: Social media, Society, Chi-square test, hypothesis testing.

\section{INTRODUCTION}

Social Networking Sites have become prominent part of life for many people today, be it youth, the working lot $\&$ even the elder people. There are more than 2.3 Billion worldwide active social networking sites users. Most people engage with social networking sites without thinking, what are its effects on their lives, whether it is positive or negative. According to various research studies in the field of online social networks, it has been revealed that these sites are impacting the lives of the youth as well as the society greatly. Social networking sites play a huge role in modern day politics \& are one of the most valuable assets that political parties use to gain votes. We can take a look at the recent election campaigns in our country \& see how all the parties have spent millions on social networking sites to help tarnish each other's name \& policies.

Social networking has changed the way people interact with each other forever. Also there are 
some negative effects which include identity theft, cyber bullying, decreased social interaction in real life, and social isolation. Increase in mobile social networking could possible cause future health problems. The most common positive impact of social media was that it allowed kids to stay in touch with past and present friends throughout the changes in their lives: school, job, and team changes, hospital stays, studying abroad, etc.

In this article we study the positive as well as negative effect of social media on society. We collected the primary data through questionnaire from various areas. We used the graphical representation and testing of hypothesis for statistical analysis purpose.

\section{OBJECTIVES}

1) To study gender -wise distribution of use of different social networking sites

2) To study proportion of male and female users of SNS in rural and urban area

3) To study various effects of social networking sites on lifestyle of users
4) To study impact of social networking sites on personal \& social life

5) To study the frequency at which users share their personal, social \&economic aspects through SNS.

\section{METHODOLOGY}

For this study we have collected 300 samples by simple random sampling. By using proportion method we took 150 are from rural area and remaining 150 are from urban area.

Ghunaki.

For rural area, 1] Chavare 2] Talsande 3]

For urban area, 1] Rajarampuri 2] Shahupuri 3] Ruikar colony

\section{STATISTICAL TOOLS USED}

1. Graphical Representation

2. Testing of hypothesis

3. Theory of Attribute

Software's used: 1. MS-Excel 2. MS-Word 3. RSoftware

\section{GRAPHICAL REPRESENTATION}

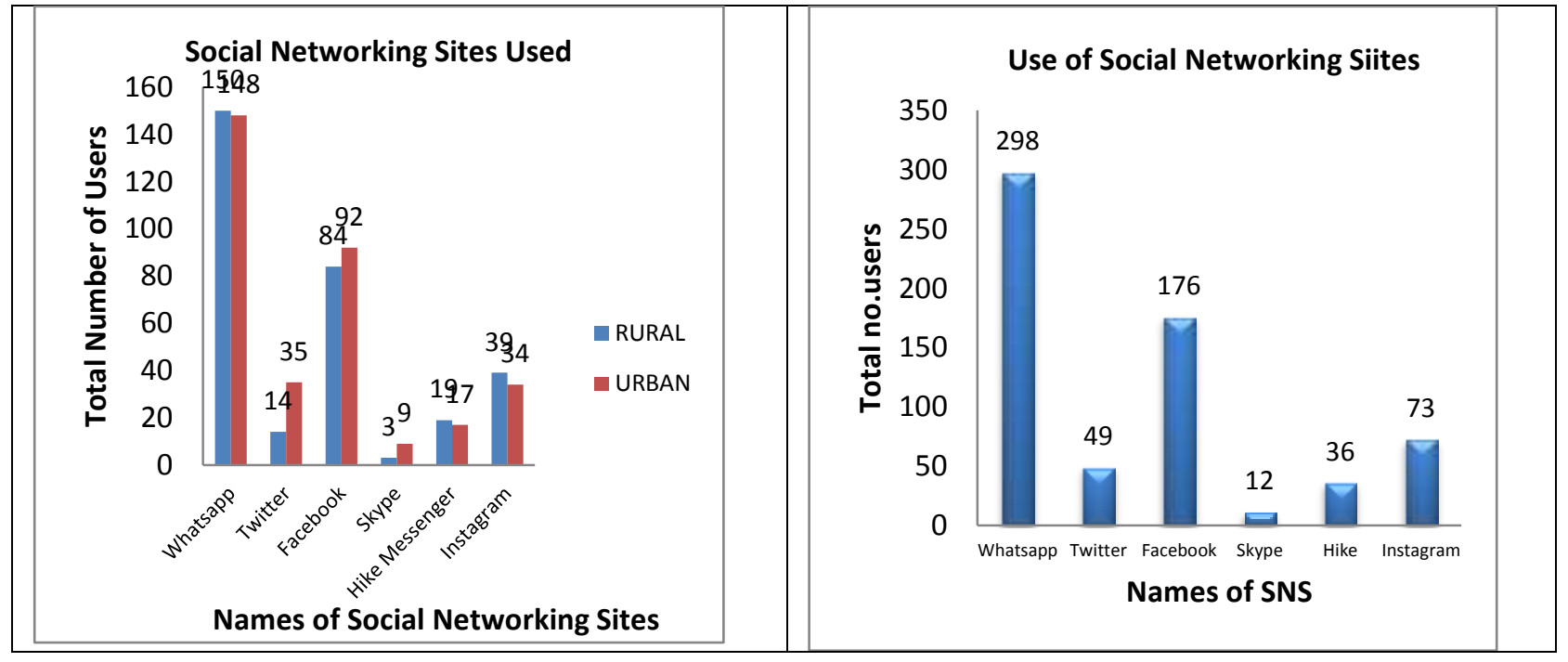




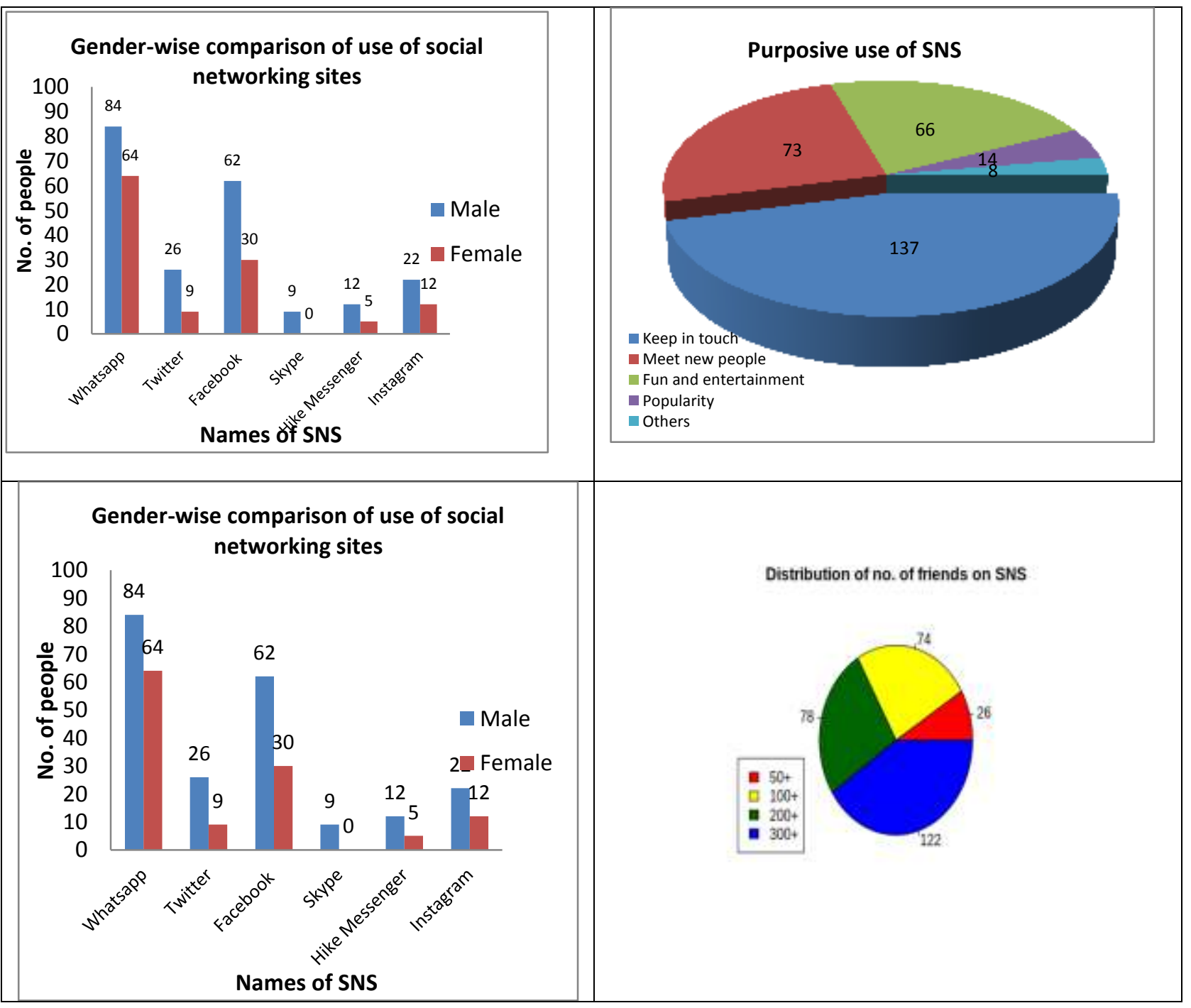

\section{TESTING OF HYPOTHESIS}

\section{A) Test for Equality of Proportion of Social} Networking Sites Male Users in Rural and Urban Area:-

$H_{0}$ : There is no significant difference between proportions of SNS users in rural and urban area for male

$H_{1}$ :There is significant difference between proportions of SNS users in rural and urban area for male

$$
\mathrm{Z}_{\mathrm{cal}}=0.4695 \quad \mathrm{Z}_{\mathrm{tab}}=1.96 \text { at } 5 \% \text { level of }
$$

B) Test for Equality of Proportion of Social Networking Sites Female Users in Rural and Urban

$H_{0}$ : There is no significant difference between proportions of SNS users in rural and urban area for female

$H_{1}$ :There is significant difference between proportions of SNS users in rural and urban area for female

$$
\mathrm{Z}_{\mathrm{cal}}=0.4678 \quad \mathrm{Z}_{\mathrm{tab}}=1.96 \text { at } 5 \% \text { level of }
$$
significance

\section{C) Test for Independence between Area and SNS Users}

$H_{0}$ : SNS users and area are independent. Vs. $H_{1}$ : SNS users and area are not independent.

$$
\lambda_{\text {cal }}^{2}=0.2199 \quad \lambda_{\text {tab }}^{2}=3.841 \text { at } 5 \% \text { level of }
$$

significance 
D) Test for Independence between Area and Effects of Social Networking Sites on Lifestyle

$H_{0}$ : Area and effects of SNS on lifestyle are independent

$H_{1}$ : Area and effects of SNS on lifestyle are not independent.

$\lambda_{\text {cal }}^{2}=2.2597 \quad \lambda_{\text {tab }}^{2}=3.841$ at $5 \%$ level of significance

Test of Attribute: Association and Colligation between SNS Users and Area.

Coefficient of Association $(Q)=0.0549$

Coefficient of Colligation $(Y)=.0274$

Fitting of distribution

A) To Check Whether Discrete Uniform Distribution is good fit for Given Data or not:-

$H_{0}$ : Sharing of personal social and economic information on SNS is uniformly distributed over the rural area

$H_{1}$ : Sharing of personal social and economic information on SNS is not uniformly distributed over the rural area.

$\lambda_{\text {cal }}^{2}=83.52 \quad \lambda_{\text {tab }}^{2}=15.507$ at $5 \%$ level of significance

B) To Check Whether Discrete Uniform Distribution is good fit for Given Data or not:-

$H_{0}$ : Sharing of personal social and economic information on SNS is uniformly distributed over the urban area

$H_{1}$ : Sharing of personal social and economic information on SNS is not uniformly distributed over the urban area.

$\lambda_{\text {cal }}^{2}=146.56 \quad \lambda_{\text {tab }}^{2}=15.507$ at $5 \%$ level of significance

\section{CONCLUSION}

In the world with over $70 \%$ of internet users' active on social networks, who spend at least one hour a day on average on those social networks, we have to conclude that social networks have become a sort of reality in which people communicate, interact, and obviously trust. We also have to be aware that over $60 \%$ of those users access social networks via mobile devices, with strong indicators that this percent will only increase in the future years. In our study we conclude that, Whatsapp, Hike Messenger and Instagram are used more in rural area than in urban area.
99\% people in Kolhapur district used Whatsapp while nearly 59\% people used Facebook.

To keep in touch with family and friends nearly $46 \%$ people use social networking sites.

In rural area male users of social networking sites are greater in number than female users. In urban area male users of social networking sites are greater in number than female users. Impact of social networking sites on social life in urban area and rural area is positive. Health and academic performance in rural area is more positively impacted.

A male as well as female user of social networking sites in rural is less than urban area. The area and users of social networking sites are independent. Effect of use of different social networking sites on lifestyle and area are independent. Users of social networking sites and area are positively associated. Sharing of personal, social and economic aspects on social networking sites is not uniformly distributed over the rural area and urban area.

\section{REFERENCE}

1. Becker, Mark W., Reem Alzahabi, and Christopher J. Hopwood. Media Multitasking is Associated with Symptoms of Depression and Social Anxiety. Cyberpsychology, Behavior, and Social Networking 16, no. 2 (2013): 132-35.

2. Bryfonski, Dedria. The Global Impact of Social Media. 2011 ed. Detroit, MI: Greenhaven Press. 224.

3. Campbell, Marilyn (2005) Cyber bullying: An old problem in a new guise? Australian Journal of Guidance and Counseling, Australian Academic Press, 2005, 76.

4. Mark W. Becker, Reem Alzahabi, and Christopher J. Hopwood. Cyberpsychology, Behavior, and Social Networking. February 2013 